References:

1. DE GOES, H., (1960) "The Radio-humeral meniscus and its relation with tennis elbow". Archives of Interamerican Rheumatology, 111:4 December, 1960.

2. BOSWORTH, D. M., “Surgical Treatment of Tennis Elbow”. Journ. Bone Joint Surg. 47A:December, 1965.

3. GARDEN, R. S., (1961) “Tennis Elbow”. Journ. Bone Joint Surg. 43:100.

4. KOPELL, H., and THOMPSON, W. "Peripheral Entrapment Neuropathices", p. 125. The Williams and Wilkins Co., Baltimore 1963.

\title{
INJURIES TO THE UPPER LIMB IN JUDO
}

PHYLLIS ELLIOTT, M.B., Ch.B.

Physiology Dept. Sheffield University.

Hon. Medical Officer, British Judo Association.

There are a variety of ways in which injuries to the upper limb may be sustained in Judo, and they may affect either the person who is applying a technique (Tori) or the person on whom the technique is applied (Uke).

Considering Uke first, the causes of injury to the upper limb fall into two main categories - armlocks and throws. An armlock is a technique applied to the elbow, with the arm in either a bent or a straight position, which imposes strain on the ligaments and would, if continued, cause dislocation; Uke therefore submits and Tori gains a point in contest. However, occasionally in contest, the lock may be applied over-enthusiastically by Tori, or Uke may be a little slow in submitting due to attempting first to escape from the lock. In these cases, especially in the case of a bent armlock, the medial ligament of the elbow may be damaged. In Judo, the elbow is the only joint to which locks may be applied; Knee-locks used to be allowed but were banned several years ago, presumably because they were too liable to cause injury. However, while fighting, other joints may be accidentally injured - for example, fingers or wrists due to the hand becoming trapped in the opponent's jacket - or a shoulder may be subjected to strain by a badly applied elbow-lock.

In the case of throws, injury may be caused either by landing on the point of the shoulder, when Uke has not been turned sufficiently to cause him to land on his back, or by a fall on the outstretched hand if for some reason Uke puts an arm out straight as he is being thrown. Landings on the point of the shoulder produce acromio-clavicular lesions (sufficiently frequent that this is called "black-belt shoulder" by the competitors!), fractured clavicles and occasionally sterno-clavicular lesions. The fall on either an outstretched hand, or sometimes the elbow, can of course produce many different injuries; the one. I have seen most frequently is dislocation of the elbow, plus the occasional dislocated shoulder.

The person applying the techniques is of course at less risk, but with some throws, he may also land on the point of his shoulder while throwing his opponent. His other major source of possible injury is again trapping of the hand in the opponent's jacket while throwing him, or during groundwork. Sometimes the wrist will be subjected to considerable strain if he allows it to become hyper-extended while throwing his opponent, instead of keeping the hand in line with the fore-arm.

All of the above may make Judo sound a very dangerous sport; however, a large proportion of people practising Judo do so for many years without suffering more than the occasional bruise. The above observations have been gleaned over 14 years in Judo, both as a participant and as Medical Officer at many of the major Judo events. 